\title{
Influence of Gender Difference on Language*
}

\author{
Bin Wang \\ Foreign Languages Department \\ Liaoning Institute of Science \&Technology \\ Liaoning, China 117004
}

\begin{abstract}
Undoubtedly, the sociolinguistics circle has admitted that there is a close relationship between language and gender. This article provides some examples of different languages between men and women. It demonstrates the linguistic difference with strong evidence and presents new ideas and demonstrates the correctness.
\end{abstract}

Keywords—social status; difference; male language way

\section{INTRODUCTION}

There are differences between men and women, which have become indisputable facts. In recent years, discussions on the linkages between language and gender have become topics of frontier research in terms of language structure, vocabulary, usage of special languages, and the respective social roles in context. It would further explore the hot topics in the field from the following three aspects of some textual research and theory.

\section{THE REASON WHY WOMAN'S LANGUAGE CAN'T BE LIKE MAN'S LANGUAGE"}

We have a controversial topic. "Why does women's language differs from men's language? In other words, what factors have made women's language be more standard and more polite than men's language? This gender difference exists in Eastern and Western societies. And even in the same area of life, the languages of men and women are completely different.

If we think that the language has certain value and social practice, we would find the answer easily. It is giant network that closely links society, politics, culture and chronology within the society. For example, in a society where men are superior to women, the difference between the languages of men and women is only one aspect of all the major differences in the scope. Undoubtedly, language behavior is inseparable from society and its own value. Differences between the languages of men and women can only indicate the distance between women and men. This controversial

*Title of the Project: Based on Stratification and Diversified Practice, Applied Foreign Language Teaching Model Research \& Practice

Project No.: JG16DB232 (Liaoning Province Education \&Science

Planning Projects in 13th Five-Year, 2016)

Title of the Project: Position Ability Oriented, Characteristic of

Additional Practice Term, Construction of the Training System of English Professional Talents

Project No: 1st Batch of the Projects of the Reform and Development of Education and Teaching in Liaoning Institute of Science \& Technology issue is the focus of this article.

Through observation, linguists found that women were aware of their low social status. Therefore, they are accustomed to using more standard language to try to obtain equality or gain higher recognition of the status. In a sense, they fight the injustice of male society with "armed rise". "It is clear that women generally can't accept their status of inferiority. And the society doesn't recognize female status. They have been fighting to change this irrational phenomenon." said by the linguist Key (1990: Fasold). Trudgill (1983a: 167-168, Fasold), another American linguistics expert said: "Women are often closely related to parenting and cultural communication. Therefore, they would make plan for their children with maternal instincts They think that the reputation, status and other things are important." The status of men in society is usually determined by their position, the salary they earn and their working ability. That is to say, it is determined by their work. And how is woman? Comparing to men, it is determined by their performance. This view seems to suggest that workingclass women use less standard language than laid-off women. And they have acquired certain social status and success. However, in fact, a study from the United States shows that working-class women tend to use more standard language than housewives. The reason is clear. The former has talked to strangers for most of the time. The latter only has the talk with their families at breakfast and dinner. And then, it would have a question. The female language norms are more standardized. Can they gain social recognition? Maybe, they just want to show their wisdom and etiquette.

The second way to interpret female language norms is based on the attitude and approach of society to women differing from that of men. For example, people can forgive boys' over-extremism. However, they often would teasingly complain about the little girl's behavior, sternly rebuke or punish them at once. According to J. Holmes (1992: 173), "Women are appointed to have the social norms." Therefore, the society often looks forward to the fact that women should not make mistakes in speaking. However, it can't be always like that. Women tend to behave in a non-restrained manner. And they would deal the relationship between mother and child, and the relationship between husband and wife with this manner. Sometimes, women would also use rude expressions and dialects.

It is inconceivable that a woman could even reveal more fierce language of curses such as "God damn you", "fuck ...", 
"shit", "sabi", etc. When they were most excited, they could only squeeze out some words such as "God", "Oh! My God", and "Jesus!". They make up the vocabulary to vent feelings. According to the expert R. Lakoff, from the perspective of syntactical structure, women are accustomed to using stereotypes and petitions, such as "you are the best ......", "... can you?". However, Fasold made a conclusion. Women are accustomed to this. That is to say, they can't determine their own opinions. And they are not assertive.

There is third explanation. In order to maintain the "face", women would use language norms. Also, they would be polite. This linguistic term is a sign that people want to establish contact with others (seeing the book on Linguistics by Levinson and Brown in 1978). Perhaps we can also think that women are out for the purpose of gaining social status. They would use more normative language not only to maintain their personal face, but also to protect the communication. And then, they may avoid inconsistency in opinion or create harmonious atmosphere. We can take English students as the example. With the experiences of the author for many years as English teacher, most girls once stand up to answer questions, they always do their utmost to provide a more accurate, standard and polite sentences. Another explanation is that women are inherently superior to men in terms of language function, according to the physiology of the human brain.

In addition, women are also subjected to two different kinds of discrimination in linguistics. In other words, women are different from men in the way of language education and the manners they deal with languages or use words. Taking an English example:

Man has unfortunately made inroads into his environment.

Experienced scientists manned the spaceship. This discovery will benefit all mankind.

Obviously, "men" have replaced the entire human, masking the others - women. There are also some gender words, suggesting the "derogatory" of women and "praise" of men. Commonly, we would use pairs of the words "bachelor" ("单身汉", "光棍儿") and "spingster" (unmarried woman, old virgin). The bachelors seem to be a happy man, and they are busy sowing in barren fields. And the old virgin always make people think of the status of ugly, fragile and self-affected woman. What is more, language is also attached to the immoral sexuality for women. For example, Madam refers to the "procuress" of a brothel. Sir has nothing to do with "pander".

\section{The People Who Are More Willing to TAlK, MEN OR WOMEN}

According to traditional culture, women are talkative. And they like to express their feelings. However, are women really more talkative than men? One experiment shows that it is not the fact. The experiment was made by the expert Marjorie Swacker. He took three pictures of Flemish painter Albrecht Durer in the 15th century to men and women respectively. And then, he asked them to describe the three pictures as much as possible. And he found that the average time of describing these pictures by man was 13 minutes, and the average time of describing these pictures by the woman was 3.17 minutes. Another experiment is more interesting. When a man is in love, he is very talkative and enjoys talking to his favorite people. However, after getting married, some men became reticent. Especially, when they return to their homes after busy work, they don't want to talk with others. However, other men would still be talkative even when they were at home. On this opinion, we can observe it in public places such as parks and cinemas frequented by couples. At most of the time, men are engaging in talking. Perhaps, this is a great opportunity for men to show their charm, their knowledge and their "handsome".

\section{THE REASONS}

Linguists try to find the link between society and language. And then, it could explain the low probability of women speaking with the difference between the recognition of women in culture and that of men. Men have always played a leading role not only in domestic work, but also in the work environment. This view has been changing. However, it increasingly is unsuitable for the society. And it is still evident in many other parts of the world. People are more willing to accept man's rhetoric, long-winged reports. However, people can't accept the lady to do the same thing. Finally, the history gives men rights to speak. However, there are many situations in which they need to express their emotions. Usually, they would show the silence. Since the childhood, they were told to "calm down", "do not cry", "to be a little man" and so on. When two people have quarrel, we seldom see men talking. At the same time, if the woman is endless, the man wouldn't "swallow this tone". And even, some men would lose "demeanor". And they may use the violence to solve the problem.

\section{The LANGUAGe Difference BetweEn Men AND WOMEN}

According to the following sentences, who are more willing to speak?

"Wow, nice house!"

"You're cute in this set of clothes."

"Nice jacket."

"I like this pair of shoes, where can I buy it?"

"This little shirt is cool, I like it!"

"This shirt is very cool to wear."

Sometimes, this kind of comment seems to be old. However, it does make it easy to identify the speaker or his or her approximate age. In some languages, there is a difference in the language of men and women speak. In Indian Yana, men and women would use different languages to describe the same thing. For example "Table I": 

YANA

\begin{tabular}{|l|l|l|}
\hline Women & Men & Meaning \\
\hline Ba & Ba-na & "Dear" \\
\hline Yaa & Yaa-na & "Person" \\
\hline
\end{tabular}

The linguist Sapir also found that when men talk with others, they would use men's manners to talk. Also, women have their own way to talk with females. However, the way men talk to women is in a slightly different way. In "Table II", there is no shortage of examples in Japanese. Nancy Bonvillain has testified these examples in "Language, Culture and Communication".

TABLE II. The EXAmples IN "LANGUage, Culture AND COMMUNICATION"

\begin{tabular}{|l|l|l|}
\hline Women & Men & Meaning \\
\hline ohiya & mizu & “water” (水) \\
\hline onaka & hara & “stomach” (腹) \\
\hline oisii & umai & “delicious"(香) \\
\hline taberu & kuu & “eat” (吃) \\
\hline
\end{tabular}

In Chinese, we can also find that men would speak the dialect. For example, "儿唬" (Note: it is the dialect said by the teenager in Benxi, Liaoning province. And it means that if I lie to you, I would be your son.) There are uncivilized words such as "操" (be equivalent to the "whoops, fuck it" in English)", "妈了个巴子" (Note: northeastern dialect, such as Zhang Zuolin's tag, and it can express the anger, etc.), "奶奶 的" (men's dialect in Shandong) and so on.

\section{Conclusion}

In short, the application of language research will bring major discoveries in the structure, environment, and related aspects of society. And even, it would change individual attitudes and ways of doing things. Interestingly, the meaning of language is not superficial. The aim is to arouse people's attention to various factors that cause language differences between men and women. And it would be helpful to fill some gaps in some studies of social languages.

\section{REFERENCES}

[1] Xu Daming, et al. Contemporary Sociolinguistics [M]. China Social Sciences Publishing House, 1997 (02).

[2] Zhu Wanjin. Introduction to Sociolinguistics [M]. Hunan Education Press, 1992 (08).

[3] Fromkin \& Rodman. An Introduction to Language [J].1979: Chapter2, p34.

[4] Janet Holmes. An Introduction to Sociolinguistics [M].1990.

[5] Lakoff, R. Language and Woman's Place. Language in Society [M]. 1973, Chapter2, p45-80.

[6] Sapir, E. Male and Female Forms of Speech in Yana. In S.W. J. Teeuwen(ed.) (1929a), Donum Natalicum Schrijnen.

[7] V. Fromkin and R. Rodman. An Introduction to Language [M]. 6th edition, 1979: Chapter2, p34. 